\title{
A new technique using a rubber balloon in emergency second trimester cerclage for fetal membrane prolapse
}

\author{
Makoto Kanai1, Takashi Ashida1, Satoshi Ohira1, Ryosuke Osada1 and Ikuo Konishi2 \\ 1Department of Family and Child Nursing, and Midwifery, Shinshu University School of Health Sciences, Matsumoto, \\ Nagano, and 2 Department of Gynecology and Obstetrics, Kyoto University School of Medicine, Sakyo-ku, Kyoto, Japan
}

\begin{abstract}
Aim: Prolongation of pregnancy in cases of fetal membrane prolapse into the vagina during the second trimester is difficult using conservative therapy. After pushing the membranes back into the cervix, emergency cervical cerclage may be advantageous in improving the neonatal outcome. We have been managing membrane repositioning and emergency cervical cerclage with a technique using a rubber balloon device (known as a'mini metreu' in Japan), and we examined the efficacy of this technique in five cases.

Methods: Our management was as follows: Initially, the full bladder technique was attempted under general anesthesia. If this was not effective, amnioreduction was performed by transabdominal amniocentesis. After the membrane repositioning using a mini metreu, double suture cervical cerclage (McDonald method + Shirodkar method) was performed.

Results: The diameter of the bulging prolapsed membranes ranged from 30-84 mm, with a mean of $52 \mathrm{~mm}$. Cerclage was successfully performed in all of the five cases. Prolongation of the pregnancy period was from 22-107 days (average; 77.6 _ 28.9 days). In cases 1-4, healthy newborns were delivered, but in case 5 sudden intrauterine fetal death due to umbilical cord complications occurred at 24 weeks of gestation.

Conclusion: It appears that long-term prolongation of pregnancy is possible, when performing membrane repositioning using the mini metreu and emergency cervical cerclage for fetal membrane prolapse into the vagina.
\end{abstract}

Key words: cervical insufficiency, emergency cervical cerclage, fetal membrane prolapse, new technique, threatened premature delivery.

\section{Introduction}

When bulging prolapsed membranes develop out of the cervix into the vagina during the second trimester (Fig. $1 \mathrm{a}, \mathrm{b})$, in many cases the situation progresses to abortion or premature birth, and neonatal prognosis is poor.1-7 Since neonatal prognosis is affected by the number of weeks of gestation, the prolongation of gestation is generally attempted for as long as possible. It is difficult to extend the pregnancy period by conservative therapy, however, and keeping the mother resting in bed for a long time increases the risk of thrombosis and infection. Therefore, it is important to determine whether emergency cervical cerclage can be performed or not, after repositioning the prolapsed fetal membranes.8-11 Successful cervical cerclage not only improves neonatal outcome but also gives great merit to the mother. In spite of that, no effective management method has been established yet.12 We have been dealing with bulging prolapsed membranes using a new method that consists of repositioning the handling a rubber balloon device (called mini metreu in Japan; Fig. 2b), and conducting cervical cerclage twice. This method was applied in 5 cases, and the efficacy was examined. (The mini metreu is produced by SOFT MEDICAL Co., Ltd., 2-17-11 Yushima Bunkyo Tokyo JAPAN.)

\section{Methods}

\section{Preoperative diagnosis and management}

The sizes of the dilatation of the internal os and the bulging prolapsed membranes in the vagina are estimated using ultrasonography (Fig. 1a). If chorioamnionitis is present, the prolongation of gestation is difficult. If the infant is developed enough to be managed in the Neonatal Intensive Care Unit (NICU), we deliver the infant, however if chorioamnionitis is found when a fetus is too immature, it can be controlled using sufficient antibiotics and anti-inflammatory agents before surgery.13 If chorioamnionitis is not cured, however, our only option is to terminate the pregnancy. Likewise, if a diagnosis of chorioamnionitis is confirmed shortly after the operation, the management depends on gestational weeks and fetal growth. If chorioamnionitis is present in a case of fetal membrane prolapse during the third trimester, we deliver the infant.

\section{Anesthesia}

The surgery should be performed under general anesthesia in a Trendelenburg position. In lumbar anesthesia, the risk of inducing total spinal paralysis should be considered. Patients are conscious under lumbar anesthesia or epidural anesthesia, a Trendelenburg position is very uncomfortable for pregnant women, and fetal membrane prolapse may occur again owing to abdominal pressure. Inhalation anesthetic suppresses uterine contractions.

\section{Repositioning of prolapsed membranes}


When the vagina is filled with prolapsed membranes and the cervix is not observable (Fig. 3a), the full bladder technique is tried.14-16 When the full bladder technique is ineffective, amnioreduction is performed by amniocentesis. According to our experience, in 22-24 weeks of pregnancy, the aspiration of 250-300 mL of amniotic fluid relaxes the membranes packed densely in the vagina. Part of the collected amniotic fluid is submitted to bacterial culture, and close examination for causative bacteria of intrauterine infection is carried out. A few reports showed that the pregnancy period was successfully prolonged by conducting cervical cerclage after amnioreduction.15-18 When tense membranes started to be relaxed, repositioning of the membranes is attempted using the mini metreu (Fig. 2b). When a part of the cervix becomes visible, the cervix is picked gently with a pair of (Fig. 2a). While drawing the cervix gently, the membranes are pushed back (Fig. 3b). When the cervix is held at 4 points every $90^{\circ}$, the entire circumference of the cervix can be observed (Fig. 3c).

\section{Cervical cerclage}

To avoid the risk of recurring fetal membrane prolapsed from a slight gap, and for possible inhibition of ascending infection after the restructuring of the cervix, it is preferable to perform cervical cerclage twice. The first operation is performed using the McDonald method. After the end of the operation using the McDonald method, the mini metreu is left as it is (Fig. 4a). Teflon tape is knotted once only tentatively beforehand for tying the mini metreu together (Fig. 3d). From this point in time, the bulging of prolapsed membranes in the vagina will not occur again. Next, the second operation is performed using the Shirodkar method. The final knotting is performed at the time of tying the Teflon tape used in the Shirodkar method. At this time, the operator and the first assistant tie the Teflon tape of the McDonald method and that of the Shirodkar method, respectively, at the same time. The second assistant removes physiological saline from the mini metreu slowly, and then, removes the mini metreu through the cervix. Simultaneously, the operator and the first assistant tie the Teflon tape more tightly (Fig. 3e,f). The result after the conclusion of the cervical cerclage is shown in Figure 4b.

\section{Results}

Summarizing the five cases, the onset time of the bulging prolapsed membranes into the vagina was found from 19 to 23 weeks of gestation, and the operation was performed between 20 and 24 weeks. Estimated fetal body weight was 284-699 g (Table 1). When repositioning, the diameter of the bulging prolapsed membranes was 30-84 mm (average; $52 \mathrm{~mm}$ ). Chorioamnionitis found in Cases 1-4 was mild. The Case 5 patient completely recovered from postoperative infection, and she was stable without having any uterine contractions. The prolongation period from the membranes prolapse to parturition in cases 1-5 were: 97 days (22 weeks of gestation [wG] to $36 \mathrm{wG}$ ), 107 days ( $23 \mathrm{wG}$ to $38 \mathrm{wG}$ ), 73 days ( $22 \mathrm{wG}$ to $32 \mathrm{wG}$ ), 79 days(20 wG to $31 \mathrm{wG}$ ), and 32 days (19 wG to $24 \mathrm{wG}$ ), respectively. Each of Cases 1-4 delivered a healthy baby. Although the postoperative course of Case 5 was good, she had sudden in utero fetal demise that seemed to be attributed to an umbilical cord factor and had a stillbirth at 24 weeks of pregnancy. In the other 4 cases the operation succeeded and the mean prolongation of the pregnancy period was 89.0 _ 15.7 days.

\section{Discussion}

There has been no report on the establishment of any effective management method for bulging prolapsed membrane cases in the vagina during the second trimester. According to the review of several reports, 12 management by performing a single suture McDonald cerclage was stated in many papers, when a patient was at 14-24 weeks of gestation with the absence of fetal anomaly, membrane rupture, uterine contraction and chorioamnionitis. Using that method live birth is said to be expected in $23-55 \%$ of cases. Althuisius and co-workers 10 concluded in their randomized study that emergency cerclage reduces the risk of preterm delivery before 34 weeks of gestation and that the compound neonatal morbidity in women with cervical incompetence with prolapsed membranes compared with bed rest and antibiotics alone. Daskalakis et al.11 reported that an emergency cervical cerclage in women with a dilated cervix and bulging membranes can reduce preterm delivery before 32 weeks and improve neonatal survival compared with bed rest. Therefore, it is important to determine whether emergency cervical cerclage can be performed or not, after repositioning the prolapsed fetal membranes. The prolongation of the pregnancy period by emergency cervical cerclage performed on patients with intra-vaginal bulging prolapsed membranes was reported to be 23.9-66.0 days on average (Table 2).6-8,10,11,14,15,17 In those studies, some cases were included that were of a milder cervical insufficiency than our patients. In repositioning the prolapsed membranes, it is preferable to reduce physical pressure on fetal membranes and friction while pushing as much as possible, and at the same time, to push the prolapsed membranes back into the uterine space using a wider surface area. When cervical cerclage is performed after repositioning the membranes, tools used in repositioning must be removed from the cervix carefully so as to prevent the recurrence of membrane prolapse. Various devices such as sterilized gauze, a cotton ball and balloon devices including metreurynter have been used as the tools for repositioning.19,20 Using the mini metreu, we make repositioning of fetal membranes and cervical cerclage easy. The merits of using the mini metreu are summarized as follows: 1 In comparison with gauze and a cotton ball, pushing back using the mini metreu causes less physical pressure on the fetal membranes and less friction while repositioning. 2 In comparison with the existing balloon catheter, the rod-shape part of the mini metreu is harder, 
and pushing fetal membranes is easier. 3 It is easy to adjust the size of the balloon to the dilatation of the internal os, and to push in. 4 If the Shirodkar cerclage is performed after the McDonald cerclage, the membranes are pushed up to a high position, so the risk of amniorrhexis due to injury of the fetal membranes is small, and suturing at a level close to the internal os is possible. 5 When the Teflon tape is tied after conclusion of the cervical cerclage, the procedure of removing physiological saline from the balloon and removing the balloon through the cervix while tightening the suture is easy. As shown in the above, the merits of using the mini metreu are great, and this method seems not to be significantly affected by the experience or skill of the surgeon. Regrettably, this device is marketed only in Japan at the present.

\section{Conclusion}

The present study suggests that a much longer prolongation of the pregnancy period can be obtained and neonatal outcome seems to be favorable according to our control method in comparison with the methods reported in the past. Since the study group consisted of such a small number of patients, however, further accumulation of cases is necessary.

\section{References}

1. Christopher CR, Spinelli A, Collins ML. Ultrasonic detection of 'hourglass membranes' with funic presentation. Obstet Gynecol 1979; 54: 130-132.

2. Bulic M, Korenic B, Bjelajac P. Pregnancy outcome in cervical cerclage with repositioning of prolapsed fetal membranes. Jugosl Ginekol Opstet 1980; 20: 213-216.

3. Latta RA, McKenna B. Emergent cervical cerclage: predictors of success or failure. J Matern Fetal Med 1996; 5: 22-27.

4. Benham BN, Balducci J, Atlas RO et al. Risk factors for preterm delivery in patients demonstrating sonographic evidence of premature dilation of the internal os, prolapse of the membranes in the endocervical canal and shortening of the distal cervical segment by second trimester ultrasound. Aust N Z J Obstet Gynaecol 2002; 42: 46-50.

5. McGahan JP, Hanson F. Prolapsing amniotic membranes: detection, sonographic appearance, and management. J Perinatol 1987; 7: 204-209.

6. Wu MY, Yang YS, Huang SC et al. Emergent and elective cervical cerclage for cervical incompetence. Int J Gynaecol Obstet 1996; 54: $23-29$.

7. Ishikawa $\mathrm{K}$, Watanabe $\mathrm{H}$, Tadokoro $\mathrm{N}$ et al. Outcome of prolapsed chorioamniotic membrane: relationship between the degree of herniation, infection, and pregnancy prolongation. Am J Perinatol 2003; 20: 381-389.

8. Artmann A, Schuchardt R, Gnirs J et al. Total cervix occlusion -an efficient measure in prolapsed amniotic membranes in extreme prematurity? Z Geburtshilfe Neonatol 2001; 205: 143-146.

9. Templeman C, Ferrier A, Kluckow M. Emergency cervical suture: the obstetrician’s dilemma. Aust N Z J Obstet Gynaecol 1998; 38: $22-26$.

10. Althuisius SM, Dekker GA, Hummel P et al. Cervical incompetence prevention randomized cerclage trial: emergency cerclage with bed rest versus bed rest alone. Am J Obstet Gynecol 2003; 189: 907-910.

11. Daskalakis G, Papantoniou N, Mesogitis S et al. Management of cervical insufficiency and bulging fetal membranes. Obstet Gynecol 2006; 107: 221-226.

12. Harger JH. Cerclage and cervical insufficiency: an evidencebased analysis. Obstet Gynecol 2002; 100: 1313-1327.

13. Matsuda Y, Yunohara N. Effects of urinary trypsin inhibitor in patients at risk for premature labor with a bulging fetal membrane. Fetal Diagn Ther 2002; 17: 69-74.

14. Scheerer LJ, Lam F, Bartolucci L et al. A new technique for reduction of prolapsed fetal membranes for emergency cervical cerclage. Obstet Gynecol 1989; 74: 408-410.

15. Oleszczuk J, Leszczynska-Gorzelak B, Szymula D et al. Amniocentesis and mother's bladder overfilling in operative treatment of advanced cervical incompetence. Ginekol Pol 2001; 72: 1116-1120.

16. Ochi M, Ishikawa K, Itoh H et al. Aggressive management of prolapsed fetal membranes earlier than 26 weeks' gestation by emergent McDonald cerclage combined with amniocentesis and bladder overfilling. Nippon Sanka Fujinka Gakkai Zasshi 1994; 46: 301-307.

17. Makino Y, Makino I, Tsujioka $\mathrm{H}$ et al. Amnioreduction in patients with bulging prolapsed membranes out of the cervix and vaginal orifice in cervical cerclage. J Perinat Med 2004; 32: 140-148.

18. Locatelli A, Vergani P, Bellini P et al. Amnioreduction in emergency cerclage with prolapsed membranes: comparison of two methods for reducing the membranes. Am J Perinatol 1999; 16: 73-77.

19. Tsatsaris V, Senat MV, Gervaise A et al. Balloon replacement of fetal membranes to facilitate emergency cervical cerclage. Obstet Gynecol 2001; 98: 243-246.

20. Schumann K. Variations of the Holman method for reducing prolapsed fetal membranes. Variations of the Holmanmethod for reducing prolapsed fetal membranes. Geburtshilfe Frauenheilkd 1986; 46: 877-878. 
Table1 five cases who were performed emergency cervical cerclage with our management

\begin{tabular}{|c|c|c|c|c|c|c|c|c|c|c|c|c|c|c|c|c|c|c|c|c|}
\hline \multirow[b]{2}{*}{ case } & \multirow[b]{2}{*}{ age } & \multicolumn{2}{|c|}{ gravida } & \multicolumn{2}{|c|}{ BPM } & \multicolumn{2}{|c|}{ cerclage } & \multicolumn{5}{|c|}{ findings of admission } & \multirow[b]{2}{*}{ course of delivery } & \multicolumn{2}{|c|}{ delivery } & \multirow{2}{*}{\begin{tabular}{|l} 
newborn \\
weight(g)
\end{tabular}} & \multicolumn{2}{|c|}{ apgar score } & \multicolumn{2}{|c|}{ prolonged pregnancy } \\
\hline & & G & $\mathbf{P}$ & wG & day & wG & day & WBC & CRP & \begin{tabular}{|l} 
dilatation of \\
int. os $(\mathrm{mm})$
\end{tabular} & \begin{tabular}{|l|} 
diameter of \\
BPM $(\mathrm{mm})$ \\
\end{tabular} & EFBW(g) & & wG & day & & $1 \mathrm{~m}$ & $5 \mathrm{~m}$ & \begin{tabular}{|c|} 
since \\
BPM(days)
\end{tabular} & \begin{tabular}{|c|}
$\begin{array}{c}\text { since } \\
\text { cerclage(days) }\end{array}$ \\
\end{tabular} \\
\hline 1 & 30 & $\mathbf{0}$ & 0 & 22 & 5 & 24 & 1 & 4700 & 0.3 & 27 & 45 & 484 & OLP $\rightarrow$ NVD & 36 & 4 & 2135 & 8 & 9 & 97 & 87 \\
\hline 2 & 32 & 1 & 1 & 23 & 3 & 24 & $\mathbf{0}$ & 8260 & 0.22 & 16 & 30 & 688 & OLP $\rightarrow$ NVD & 38 & 5 & 3028 & 9 & 9 & 107 & 103 \\
\hline 3 & 37 & 1 & 1 & 22 & 1 & 22 & 1 & 8830 & 0.21 & 28 & 84 & 699 & OLP $\rightarrow$ NVD & 32 & 3 & 2094 & 5 & 7 & 73 & 73 \\
\hline 4 & 40 & 3 & 2 & 20 & 1 & 21 & 2 & 10450 & 2.1 & 26 & 44 & 284 & $\mathrm{OLP} \rightarrow \mathrm{C} / \mathrm{S}(*)$ & 31 & 3 & 1516 & 6 & 8 & 79 & 71 \\
\hline 5 & 34 & 2 & 0 & 19 & 3 & 20 & 6 & 16550 & 4.72 & 28 & 57 & $357(20 w 5 d)$ & sudden IUFD $(* *)$ & 24 & $\mathbf{0}$ & 580 & - & - & 32 & 22 \\
\hline
\end{tabular}

BPM:bulging prolapsed membranes

wG: weeks of gestation

EFBW:estimated fetal body weight OLP; onset of labor pain

NVD; normal vaginal delivery

$\mathrm{C} / \mathrm{S}$; cesarean section

*;previous $\mathrm{C} / \mathrm{S}$, **; cord factor 
Table2

The prolongation period from the membranes prolapse to parturition with emergency cervical cerclage for fetal membranes prolapse into the vagina in second-trimester in previous reports

\begin{tabular}{|c|c|c|c|c|c|}
\hline \multirow{2}{*}{ author } & \multirow{2}{*}{ year } & \multicolumn{2}{|r|}{ case } & \multicolumn{2}{|c|}{ prolongation period } \\
\hline & & number & outline & mean(days) & SD \\
\hline Daskalakis G, et.al. & 2006 & 29 & 18-26wG, incompetent cervix & 61.6 & 27.3 \\
\hline Makino Y, et.al. & 2004 & 8 & 19-24wG, amnioreduction & 32.9 & 46.2 \\
\hline Althuisius SM, et.al. & 2003 & 13 & before $27 w G$, incompetent cervix & 54 & 47 \\
\hline Ishikawa K, et.al. & 2003 & 10 & no sign of infection & 23.9 & ND \\
\hline Z Artmann A, et.al. & 2001 & 19 & 20-27wG, incompetent cervix & 66 & ND \\
\hline Tsatsaris V, et.al. & 2001 & 25 & incompetent cervix & 31 & ND \\
\hline Wu MY, et.al. & 1996 & 21 & BPM were 8 cases & 58 & 56 \\
\hline Ochi M, et.al. & 1994 & 18 & before $26 w G$, incompetent cervix & 35.2 & 39.7 \\
\hline
\end{tabular}


Fig.1 fetal membranes prolapse into the vagina as shown as Fig.3a)

a) ultrasonographic finding

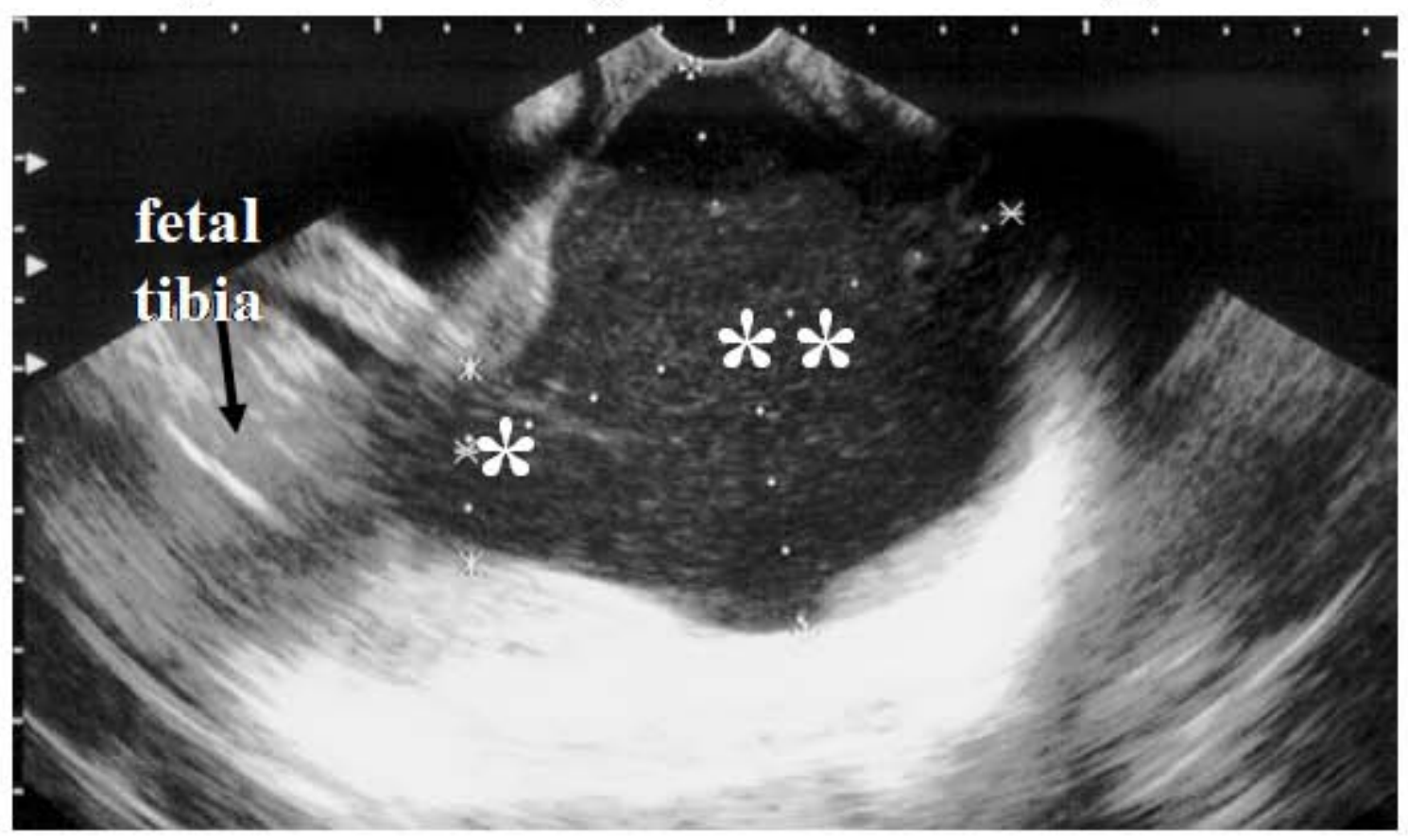

*:Diameter of dilated internal os $28 \mathrm{~mm}$

** :Diameter of bulging prolapsed membranes

$84 \times 82 \mathrm{~mm}$ b)macroscopic finding

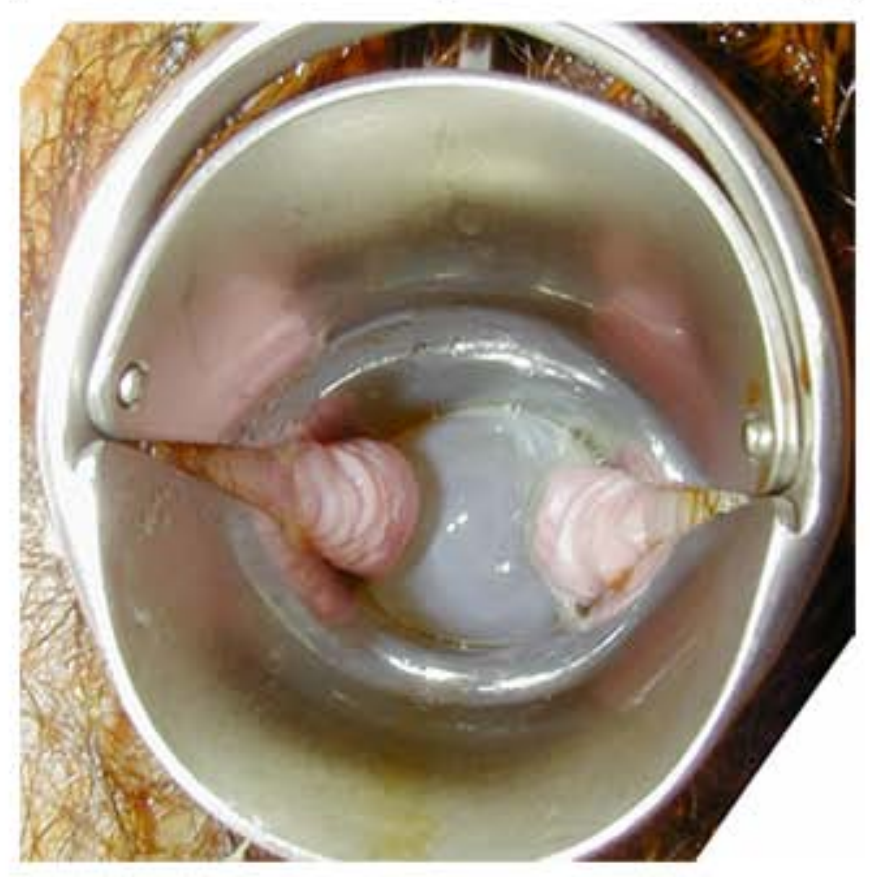




\section{Fig.2 devices for using in our procedure}

a) plain clamp

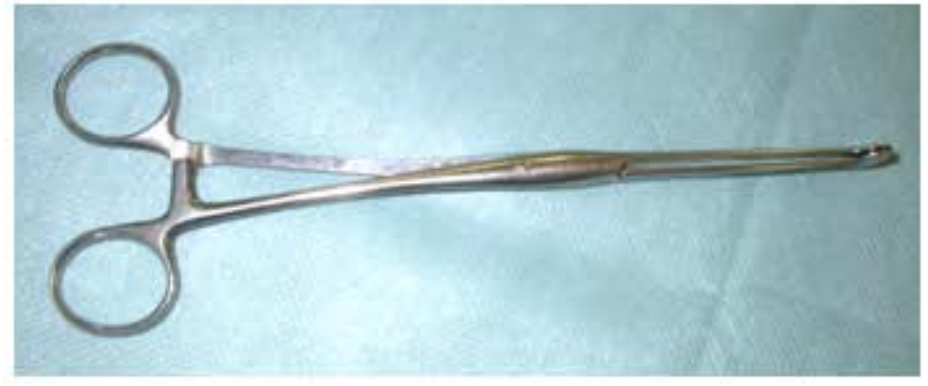

b)Metreurynter(minimetreu, SOFT MEDICAL Co, Ltd,JAPAN)

(Above) before injection of physiological saline (below) after $20 \mathrm{ml}$ injection of physiological saline

c) How to have the metreurynter
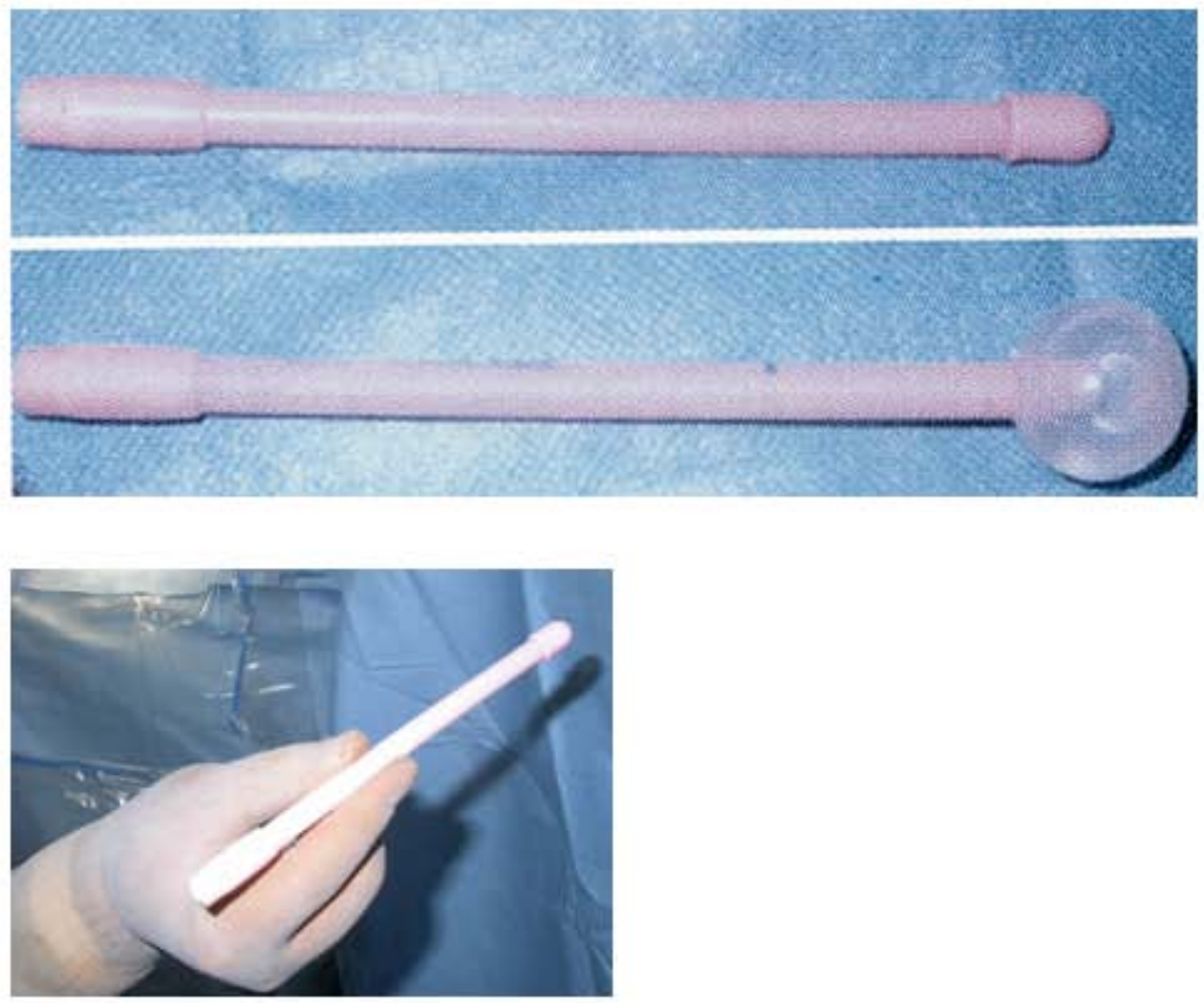


\section{Fig.3 Our procedure of emergency cervical cerclage}

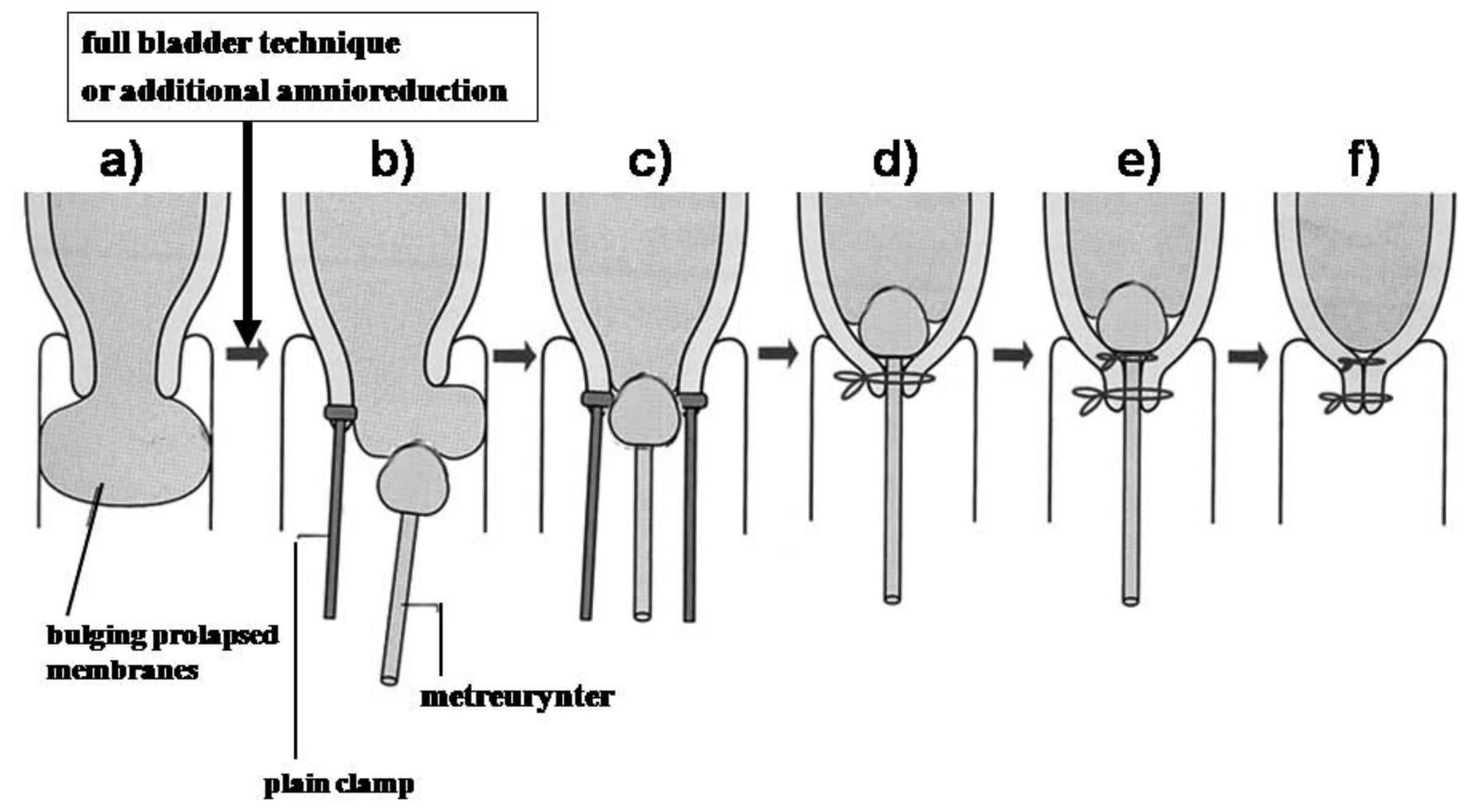




\section{Fig.4 The pictures of our methods}

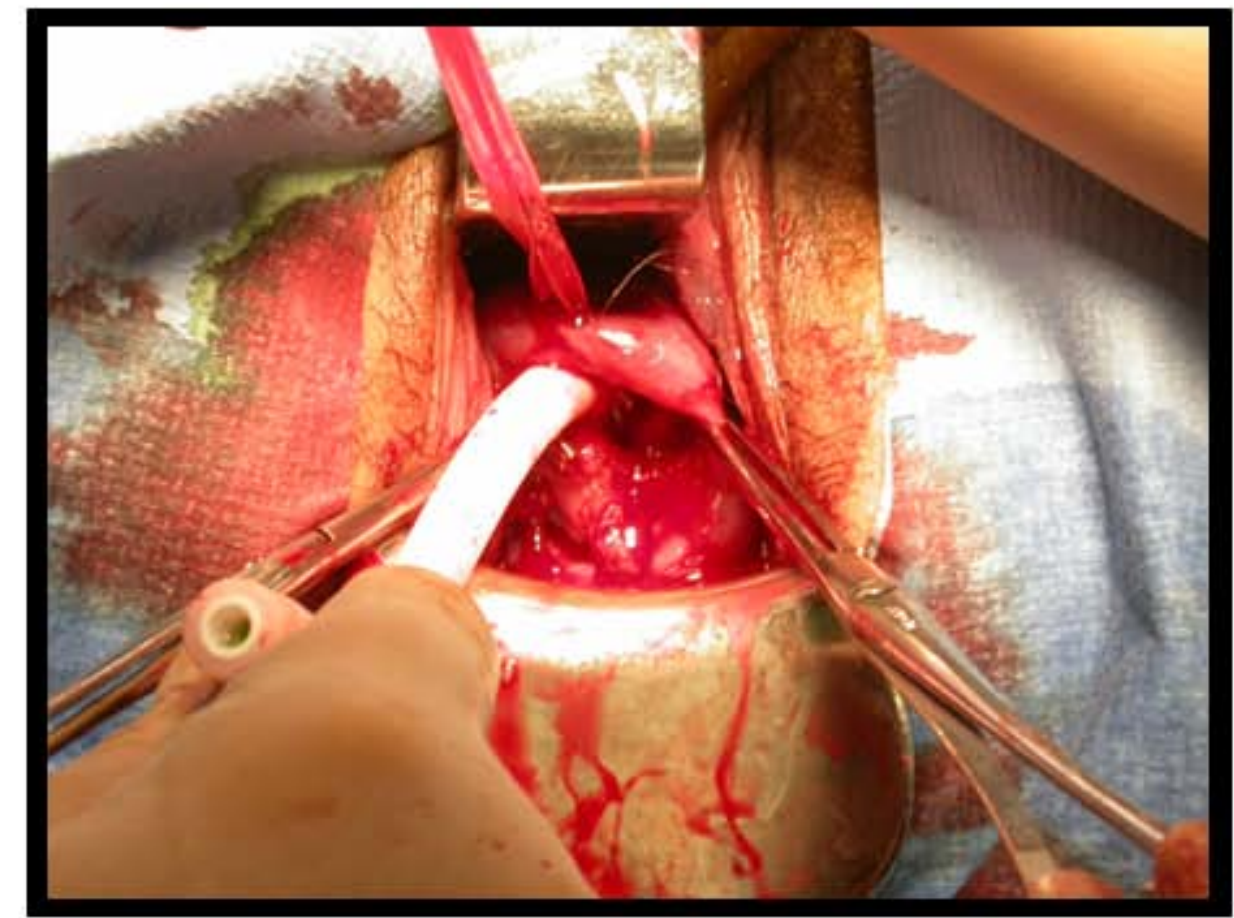

a) just before as shown as Fig.3d)

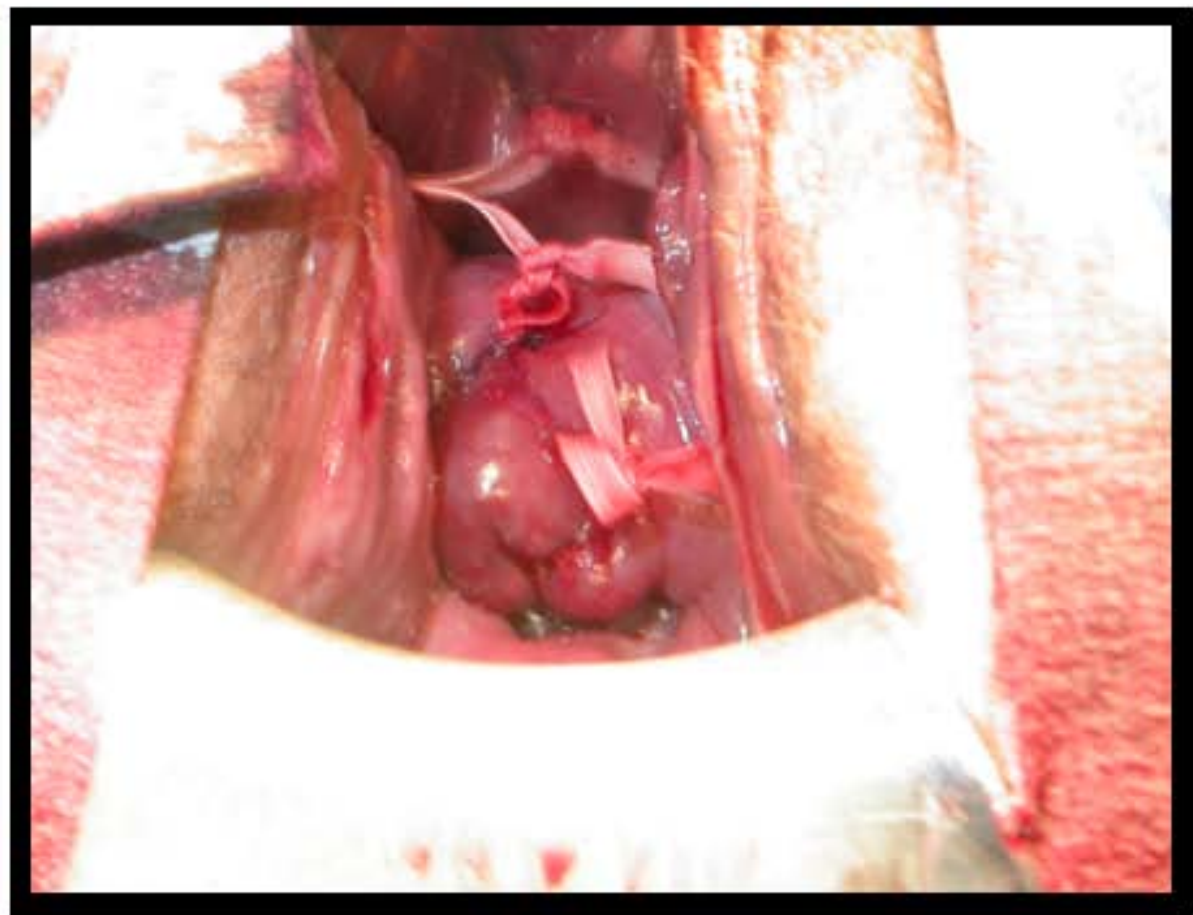

b) just as shown as Fig.3f) 